\title{
ИНФОРМАЦИОННАЯ БЕЗОПАСНОСТЬ: СОЦИОЛОГИЧЕСКАЯ ПЕРСПЕКТИВА ПОНЯТИЯ
}

\begin{abstract}
Аннотация: В работе ставится проблематизация понятия информационной безопасности в предметном поле сочиологического знания. Анализируются традиционные определения информационной безопасности. Предлагается подход к структурированию информационной среды и соответствующему представлению об информационной безопасности в широком и узком смысле этого слова. Задается понимание информационной безопасности как обеспечение безопасности соџиальных практик информаиионной среды в условиях роста интенсивности информачионных потоков и устаревания информации. Review: The article discusses a topical issue of the definition of information security within the object field of sociological knowledge. The author analyzes traditional definitions of information security, and she offers an approach towards structuring the information environment and the attitudes to information environment both in the broad and narrow understanding of the term. The author provides for the understanding of information security as security of social practices of the information service in the conditions of growing intensity of information streams and outdating information.
\end{abstract}

Ключевые слова: Соииология, безопасность, информация, инфосреда, киберпространство, современность, практики, актуальное/виртуальное, социальное, ускорение/устаревание

Keywords: social studies, security, information environment, information, cyber-space, modern time, practices, actual/virtual, social, speed-up/outdate

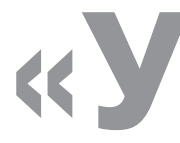

скользающая ситуация» современной жизни, нарастание сложности, многоаспектности социальных практик, рост скорости их протекания связаны с ростом интенсивности информационных процессов в обществе и возрастающей скоростью устаревания информации. Подобная ситуация вызывает к жизни новые риски и угрозы, одновременно умножая прежние. Риски и угрозы являются основными параметрами, с помощью которых сегодня прогнозируются и решаются любые социальные проблемы: будь то государственное управление, связанное с постоянным реформированием социальных структур, будь то социально-экономические решения, принимаемые различными другими социальными субъектами. Риски и угрозы для системы общества формируются наличием/отсутствием информации и возрастающей скоростью устаревания инфор- мации. Причиной тому и другому является рост интенсивности коммуникаций в обществе.

В российском обществе сформировался государственный, нормативно-правовой подход к понятию информационной безопасности. Информационная безопасность определяется как состояние защищенности информационной среды ${ }^{1}$. Этот вид безопасности рассматривается как составляющий национальной и государственной безопасности. В Доктрине информационной безопасности Российской Федерации сформулированы основные положения государственной политики обеспечения информационной безопасности России. Развивается правовое обеспечение информационной безопасности. В 2006 году был принят закон

\footnotetext{
${ }^{1}$ Доктрина информационной безопасности Российской Федерации. Утверждена Президентом РФ 9 сентября 2000 г., № Пр-1895 // Российская газета. 2000. 28 сент.
} 


\section{Национальная безопасность 4(27) • 2013}

«Об информации, информационных технологиях и о защите информации: федеральный Закон РФ»².

Первоначально появление проблемы информационной безопасности связывают с телекоммуникационной революцией. А если сказать проще, - с появлением компьютера. Традиционно параметры этого понятия принято осмысливать в технических и психологических характеристиках. К примеру, В. Н. Илюшенко определяет информационную безопасность как защиту информации и защиту от информации ${ }^{3}$. Это различение на два вида информационной безопасности, в частности, развивает С. П. Расторгуев ${ }^{4}$. Он отмечает, что информационная безопасность, являясь составляющей национальной безопасности, имеет два направления: безопасность информации (защита информации) и безопасность от информации (защита от «опасной», неадекватной картине мира информации). Оба эти направления взаимосвязано реализуются как в гуманитарной, так и в технической сферах. При этом информационная безопасность в той или иной степени присутствует при обеспечении всех видов безопасности, начиная от экологической и заканчивая информационной. Подобное же видение информационной безопасности мы находим в работах Р. М. Юсупова. Он утверждает, что информационная безопасность соответствующего субъекта (личность, общество, государство, любая система) может быть определена как состояние, в котором ему (субъекту) не может быть нанесен существенный ущерб путем воздействия на его информационную сферу ${ }^{5}$. Отметим, что С. П. Расторгуев считает, что отдельно информационная безопасность выделена только потому, что требует наличия соответствующих технологий и специалистов ${ }^{6}$.

\footnotetext{
${ }^{2}$ Российская Федерация. Законы. Об информации, информационных технологиях и о защите информации: Федеральный Закон РФ // Российская газета. 2006. 29 июля.

${ }^{3}$ Илюшенко В. Н. Информационная безопасность общества / Учебное пособие для ВУЗов. - Томск: Томский государственный университет систем управления и радиоэлектроники, 1998. С. 3.

${ }^{4}$ Расторгуев С. П. Основы информационной безопасности / Учеб. пособие для студ. высших учебных заведений. - М.: Издательский центр «Академия», 2009.

${ }^{5}$ Юсупов Р. М. Информационное обеспечение национальной безопасности // Национальная безопасность № 7/8, 2010. С. 87.

${ }^{6}$ Расторгуев С. П. Основы информационной безопасности / Учеб. пособие для студ. высших учебных заведений. - М.: Издательский центр «Академия», 2009. С. 19.
}

На наш взгляд, более функциональным из определений (т.е. в большей мере дифференцированно объясняющим круг проблем информационной безопасности) является определение М. В. Арсентьева. Он отмечает, что информационная безопасность - это снятие информационной неопределенности относительно объективно и субъективно существующих потенциальных и реальных угроз за счет контроля над мировым пространством и наличия возможностей, условий и средств для отражения этих угроз, что в совокупности определяет уровень (степень) информационной безопасности каждого субъекта. ${ }^{7}$ Мы разделяем утверждение, что в содержании информационной безопасности ключевым является контроль за информацией, циркулирующей в мировом пространстве, а также наличие возможностей и средств для отражения возникающих угроз. Это определяется и предполагает

- возможность доступа к информации;

- наличие собственного высокого информационного потенциала (ресурсов);

- независимость в использовании собственного информационного потенциала;

- средства защиты этой части потенциала (правовые, технические, специальные и др.);

- определение защищаемой части собственного информационного потенциала за счет соотнесения с информационным потенциалом других субъектов;

- создание возможностей и условий для обогащения своего собственного информационного потенциала за счет потенциала других субъектов, в том числе и находящегося под защитой, что определяется существующей конкуренцией, соперничеством и противоборством. ${ }^{8}$

Приведенные характеристики информационной безопасности особенно актуализируются в понятиях информационной войны и информационного противоборства (М. В. Арсентьев, С. Н. Бухарин, С. П. Расторгуев, В. В. Цыганов, А. И Ивлева и др.) Многие авторы пишут о кибернетической безопасности и кибернетической войне (А. Д. Еляков, А. В. Тонконогов и др.)

Но, на наш взгляд, важно развить понимание того, что информационная безопасность затрагивает не только проблему эффективности политики государ-

\footnotetext{
${ }^{7}$ Арсентьев М. В. К вопросу о понятии «Информационной безопасности» // Информационное общество, 1997. № $4-6$. C. $48-50$.

${ }^{8}$ См. там же
} 
ства в обеспечении национальной и государственной безопасности в информационной среде, не только проблему защиты информации или проблему информационного противоборства различных социальных субъектов. Считаем, что определение информационной безопасности как «защита информации и защита от информации», нуждается в переосмыслении.

В целом, в определении безопасности общества как системы мы придерживаемся подхода, утверждающего о безопасности как устойчивости социального порядка в условиях возрастания девиации/варьирования коммуникации. С этих позиций информационная безопасность, как защита информации и защита от информации субъекта, выступает существенным аспектом понятия безопасности общества. Для утверждения такой позиции мы отталкиваемся, в том числе, от синергетической методологии ${ }^{9}$, позволяющей определять природу системы общества как информационную.

Важно понимать, что становление «информационного общества» и развитие информатизации несут за собой такие особенности социальной жизни как рост «значимости информации», ее «скорость и многообразие» и, наконец, «устаревание информации». Спектр рисков и угроз, который вырабатывает современность, представленная нарастанием скорости и многообразия информации, велик. Их осмысление, систематизация еще предстоят. В свое время Э. Тоффлер убедительно показал суть этих угроз в работе «Шок будущего». Он отмечал, что скорость и временность социальной ситуации возрастают несоразмерно возможностям человека. Сегодня человек, организация, другие социальные субъекты формируют новые практики поведения, направленные на обеспечение безопасности своих интересов. Это выражается в росте временности вещей в жизни человека, временности места пребывания, временности в отношениях между людьми, временности существования организации и сотрудничества с организацией, и, наконец, временности самой информации, идей, смыслов. «Для того чтобы выжить, предотвратить, то, что мы назвали шоком будущего, индивид должен стать бесконечно более адаптируемым и знающим, чем когда-либо раньше. Он должен искать абсолютно новые способы бросить якорь, ибо все старые корни - религия, нация, общность, семья и

\footnotetext{
${ }^{9}$ См.: Урсул А. Д., Урсул Т. А. Универсальный эволюционизм (концепции, подходы, принципы, перспективы). М., 2007; Князева Е. Н., Курдюмов С. П. Синергетика: Нелинейность времени и ландшафты коэволюции. М., 2007.
}

профессия - уже шатаются под ураганным натиском силы ускорения», - писал Э. Тоффлер..$^{10}$

Эти и многие другие особенности современной жизни, обусловленные нарастанием информационных потоков, определяют новую специфику социальных практик и, в частности, новых форм отношений между людьми. Такие особенности фиксируются в социальной теории в терминах «скорости и временности», «степени проходимости социальных ситуаций» (Э. Тоффлер), «отношения ограниченного участия» (Э. Тоффлер, 3. Бауман, С. Леш и др.), «дальнодействия и отвлеченности» (В. Е. Кемеров), «объектуализации отношений или появлении «объектцентрированной социальности» (К. Кнорр Цетина), «делокализации социальных действий, их извлечения из конкретного контекста и свободного перемещения в самых широких пространственно-временных рамках»; «контрфактуальность мышления и калькуляция рисков» (Э. Гидденс), «частично-непрерывное внимание» и «пост-многозадачное поведение, характеризующее стремление индивида быть живым узлом коммуникационной сети» (Л. Стоун).

Работа с информацией, знанием в современном обществе становится не выбором, а необходимостью. В условиях такой необходимости, социальные субъекты для реализации и защиты своих интересов, задают иные формы отношения с миром. К. Кнорр Цетина считает, что распространение экспертных контекстов и культур знания в обществе являются возможным фактором роста объектно-центрированной социальности. Повсеместное присутствие таких культур как «личности эксперта», «объектов, обладающих свойствами объектов знания», подразумевают перегруппировку социальных отношений вокруг объектов знания. «Объектцентрированная реальность»- это социальная форма, которая представляет собой оборотную сторону современного опыта индивидуализации. Объектно-центрированная среда определяет идентичность так же как ранее ее определяли сообщество и семья ${ }^{11}$. Другими словами, такая среда все в большей мере определяет интересы индивида или является гарантом реализации его интересов, их безопасности. Суть процесса «объектуализации» заключается в том, что объекты замещают

\footnotetext{
${ }^{10}$ Тоффлер Э. Шок будущего / Пер. с англ. - М.: ООО «Издательство АСТ», 2001. С. 48.

${ }^{11}$ Кнорр Цетина К. Объектная социальность: общественные отношения в постсоциальных обществах знания // Журнал социологии и социальной антропологии. 2002. T. V. № 1. С. $101-124$.
} 


\section{Национальная безопасность $4(27) \cdot 2013$}

людей как партнеров по взаимодействию и все в большей мере опосредуют человеческие отношения, делая последние зависимыми от них. Это другая культура жизни, представленная «постсоциальными отношениями». Под объектами следует понимать предметы исследовательской деятельности и инструменты этой деятельности. «Объектцентрированные» отношения характеризуются переплетением социального в его привычном значении с «другими культурами». Такой другой культурой является знание и экспертиза. Идея объекта, релевантная для понимания отношений со знанием, информацией, экспертизой, резко контрастирует с понятием инструмента, товара и повседневной вещи. Характер нынешних изменений связан с «объектуализацией», т.е. возрастающей ориентацией на объекты как источник самости, реляционной интимности, разделяемой субъективности и социальной интеграции.

Усиление роли экспертных систем выражается не только в широком присутствии технологических и информационных продуктов знания. Оно предполагает существование связанных со знанием структур и форм включенности. Новое состояние общества К. Кнорр Цетина называет обществом знания и отмечает, что это не просто общество с большим количеством экспертов, технологических и информационных инфраструктур и интерпретаций специалистов, а не участников, скорее, это общество, где культуры знания органически вплетены в ткань общества, как и целый ряд процессов, практик отношений, обслуживающих знание ${ }^{12}$. Идея объектуализации предполагает, что мы переживаем переход форм социальной связи от социальной и нормативной интеграции к объектам как партнерам по отношениям или компонентам включающей среды. Такое понимание вовсе не отрицает того факта, что определенные формы связи с объектами и посредством их существовали всегда. К. Кнорр Цетина утверждает, что именно эти формы становятся преобладающими в «постсоциальных обществах знания».

Для нас примечательно, что К. Кнорр Цетина указывает на фактор возрастания рисков, который, в том числе, управляет процессами объектуализации. Объекты могут рассматриваться как своего рода средства преодоления рисков и неудач, заключенных в человеческих отношениях. В частности, поскольку многие объекты повседневной жизни превращаются в высокотехнологичные приспособления, некоторые

\footnotetext{
${ }^{12}$ См. там же С. 109.
}

из свойств, демонстрируемых объектами в экспертных контекстах, могут привноситься в повседневную жизнь, превращая инструмент или товар в повседневную эпистемическую вещь ${ }^{13}$, обеспечивающую безопасность реализации интереса. В такой ситуации некоторые из тех требований, которые компьютеры и компьютерные программы предъявляют к своим пользователям и некоторые из возможностей, которые они предоставляют, могут быть интерпретированы как инструменты, обеспечивающие укорененность нового микропорядка жизни индивида, условия его «онтологической безопасности».

С позиции обеспечения безопасности в сложном информационном пространстве можно рассматривать анализ современности Э. Гидденса ${ }^{14}$. Он выделяет три составляющих процесса динамики современного общества: разделение пространства и времени, действие «высвобождающих механизмов» абстрактных систем и институциональную рефлексивность. Разделение пространства и времени составляет важное условие для делокализации социальных действий, их извлечения из конкретного контекста и свободного перемещения в самых широких пространственно-временных рамках. Подобный процесс предполагает существование «пустых» пространственно-временных измерений, т. е. измерений, не опосредованных конкретным местом существования социального действия. Э. Гидденс отмечает, что в досовременных обществах время и пространство были связаны между собой благодаря ситуационности места, т.е. благодаря укорененности рутинной социальной практики в местном контексте действия. Свойственное современности «опустошение» пространства и времени делает возможной все возрастающую по своим масштабам координацию социальной деятельности, субъекты которой не вступают друг с другом в физический контакт ${ }^{15}$. Эти же процессы делокализации социальной ситуации описывает в «Текучей современности» 3. Бауман. Сложно не согласиться, что подобные особенности социальной практики, прежде всего, способствуют адаптации и процветанию субъектов в условиях неустойчивости и неопределенности.

Таким же образом образуется предпосылка к делокализации социальных отношений и их новых

\footnotetext{
${ }^{13}$ См. там же. С. 121.

${ }^{14}$ Giddens A. Moderniti and self-idenliti. - Stanford (Cal.) Stanford univ. press, 1991.

${ }^{15}$ См. там же. С. 15.
} 
комбинаций в неограниченных пространственно-временных интервалах. Осуществляется «высвобождение» социальных институтов из их непосредственных социальных обстоятельств, которые становятся все более сложными, непрогнозируемыми, рискогенными и «не нужными». Делокализация институтов, в свою очередь, служит «ключевым элементом того громадного ускорения пространственно-временного дистанцирования, которое привносит модерн $\rangle^{16}$. Этот процесс осуществляется с помощью «высвобождающих механизмов», или абстрактных систем, которые включают в себя экспертное знание и «символические знаки». «Символические знаки» являются средствами социального обмена, обладают стандартной ценностью и взаимозаменяемостью в любом наборе социальных контекстов (образцом таких символических знаков являются деньги). ${ }^{17}$

Экспертное знание не исчерпывается суммой наличных научно-технических сведений, оно охватывает всю практику социальных решений и самые интимные аспекты личностного «Я». Оно содержит совокупность стандартов современной социальной жизни во всех ее проявлениях. Абстрактные системы (или высвобождающие механизмы) заключают в скобки пространство и время, лишают повседневную практику ее традиционного (местного, локального, совершающегося здесь и теперь) содержания и тем самым развивают тенденции глобализации в современном обществе. Обратим внимание, что абстрактные системы Э. Гидденс называет высвобождающими механизмами. От чего они освобождают? Они освобождают от локального, повседневного, предельно рационализируя коммуникацию/действие субъекта. Это происходит в условиях дальнейшего роста вариативности ситуаций/коммуникаций и погружения социальной жизни в состояние неустойчивости.

Третий фактор динамизма современности (по Э. Гидденсу) - ее институциональная рефлексивность. Она связана с конструирующим характером социального знания и социальных наук. Рефлексивность современности выражается в «упорядоченном использовании знания об обстоятельствах социальной жизни в качестве составного элемента ее организации и изменения» ${ }^{18}$. Постоянная ревизия наличного знания о мире порождает радикальное сомнение, которое становится одним из

\footnotetext{
${ }^{16}$ Там же. С. 18.

17 Там же.

${ }^{18}$ См. там же. C. 20.
}

важнейших экзистенциальных параметров «высокой современности». Развитие науки и техники не только повышает уровень природного и социального риска, но и ограничивает возможности его прогнозирования и однозначной оценки. Постоянное вторжение научного знания в те самые социальные и природные обстоятельства, которое это знание описывает, превращает действительность в набор «контекстуальностей», а социальное бытие личности - в постоянную ситуацию выбора. ${ }^{19}$

С нарастанием варьирования ситуации/коммуникации неизбежным становится крайняя нестабильность ситуации и эксцентричность их последствий, что объясняет центральную роль контрфактуальности мышления и калькуляций риска, как важнейших элементов в обеспечении информационной безопасности субъекта. Э. Гидденс отмечает, что если в традиционном обществе личностная самоидентичность складывается из набора последовательно смещающих друг друга психовозрастных характеристик, обладавших четкими социальными «метками» (типа инициации), то современный индивид вынужден использовать все прежние образы своего «Я» как конституирующие элементы самоидентичности в меняющемся, «контрфактуальном» социальном контексте. В процесс личностной саморефлексии оказываются вовлеченными и абстрактные системы, которые предлагают постоянно расширяющийся набор педагогических, психотерапевтических, медицинских и социопсихологических рекомендаций, заменяющих однозначную определенность традиции и повседневности.

Возрастание социального и природного риска по сравнению с традиционными обществами - имеет не только (и не сколько) количественное, сколько качественное измерение. Дело не в том, что жизнь человека стала рискованным предприятием, чем существование его предшественников, а в том, что сегодня «и для дилетанта, и для эксперта постоянным и непреложным опытом становится мышление в терминах риска». ${ }^{20}$ Климат риска парадоксальным образом связан с открытостью будущего, т.е. с осмыслением грядущих событий социального и природного порядка как, в принципе, подвластных управлению и контролю. Вмешательство современного человека в будущее регулируется с помощью непрерывного процесса калькуляции риска, который охватывает все

\footnotetext{
${ }^{19}$ См. там же. С. 97 - 98.

${ }^{20}$ См. там же. С. 125.
} 


\section{Национальная безопасность $4(27) \cdot 2013$}

сферы человеческой жизнедеятельности. Э. Гидденс отмечает, что в ситуации, где максимально просчитан завтрашний день, нет места понятиям рока, судьбы или фатума. Будущее утрачивает атрибут роковой непредсказуемости и становится территорией «контрфактуальных возможностей». ${ }^{21}$

Напрашивается вопрос: какой вид безопасности актуализирует человек и общество в ответ на рост информации? Можем ли мы обратиться к прежнему пониманию информационной безопасности в подобном контексте? Или речь идет о какой-то другой безопасности в условиях информационного общества - безопасности в условиях нарастания информационных потоков? В связи с этим, хотелось бы предложить иной ракурс видения проблемы информационной безопасности.

Обратим внимание на то, что, с одной стороны, угрозы и риски, вслед за виртуализацией социального мира (М. Кастельс, Д. Иванов), в своей массе «перемещаются» в сетевое информационное пространство. В частности, речь идет о киберпространстве. Современная Сеть является мощным очагом накопления и ускорения потока информации. При этом отметим, что в понятии информации мы выделяем утверждение о том, что информация - это новые сведения. Наше представление о понятии информации близко определению информации Н. Лумана, который понимал ее как «различение различения», т.е. всякий раз новое наблюдение второго порядка, составляющее содержание коммуникации. В этом смысле, информация наполняет вариативность коммуникации, ее девиантный/инновационный характер.

С другой стороны, с нарастанием информационных потоков и устареванием информации, общество, в лице его субъектов, вырабатывает новые социальные практики обеспечения собственного самосохранения далеко не только в виртуальной реальности киберпространства, но, прежде всего, в обычной жизни.

Для того чтобы ставить проблему «защищенности информационной среды», необходимо задать структуру этой среды или как-то иначе определить ее. Отметим, что в Доктрине информационной безопасности РФ присутствует различение информационной среды относительно интересов субъектов: личности, общества и государства, а также по отдельным сферам деятельности в обществе. В документе фиксируется понятие инфор-

${ }^{21}$ См. там же. С. 111. мационной сферы, которая дополняет понимание информационной среды. Информационная сфера представляет собой «совокупность информации, информационной инфраструктуры, субъектов, осуществляющих сбор, формирование, распространение и использование информации, а также системы регулирования возникающих при этом общественных отношений». ${ }^{22}$ Мы предлагаем более общее различение информационной среды: 1. информационная среда самого современного общества с его практиками обеспечения безопасности (широкое понятие информационного пространства) и 2. киберпространство (узкое понятие информационного пространства) как особая виртуальная среда с его специфическими свойствами. Такое различение, отталкивается от представления о двух типах социальной реальности - «актуальном» и «виртуальном» мире, - которое развивают в своих работах А. В. Говорунов ${ }^{23}$, В. И. Игнатьев ${ }^{24}$. А. В. Говорунов отмечает, что проблема виртуальной реальности - это проблема исполненности интенциональных актов. Все различия между миром реальным и миром виртуальным будут укладываться в соотношение актуального и потенциального.

Обычно, информационными угрозами называют угрозы, исходящие от киберпространства (от виртуального мира). Но для нас важно понимание того, что само современное общество, в условиях роста интенсивности информационных потоков, вырабатывает новые социальные практики не только в Сети, но и в обычном мире «актуальной реальности», которые можно считать и практиками обеспечения безопасности субъектов. Соответственно, об обеспечении информационной безопасности можно говорить в широком и узком смысле этого слова: информационная безопасность в условиях современного общества (реального социального порядка) и информационная безопасность в условиях киберпространства (виртуальной социальной реальности). В первом случае речь идет о социальных практиках, адекватных ско-

\footnotetext{
22 Доктрина информационной безопасности Российской Федерации. Утверждена Президентом РФ 9 сентября 2000 г., № Пр-1895 // Российская газета. 2000. 28 сент.

${ }^{23}$ Говорунов A. В. Человек в ситуации виртуальной реальности // Информационное общество. 2001, № 1.

${ }^{24}$ Игнатьев В. И., Владимирова Т. В., Степанова А. И. Социальная система как информационное взаимодействие: коллективная монография / В. И. Игнатьев, Т. В. Владимирова, А. Н. Степанова. - Новосибирск: Изд-во НГТУ, 2009.
} 
рости и многообразию современных коммуникаций. Во втором случае, речь идет о сетевых практиках, адекватных изменчивому виртуальному пространству. Второй тип практик обеспечения информационной безопасности составляет частный случай первого. В настоящей статье в контексте первого типа социальных практик обеспечения информационной безопасности мы попытались проследить анализ новых социальных форм современности К. Кнорр Цетины и Э. Гидденса.

И первый тип, и второй тип социальных практик сводятся, к содержанию защиты информации и защиты от информации. В итоге, мы бы предложили следующий подход к определению информационной безопасности: информационная безопасность - это обеспечение безопасности социальных практик информационной среды в условиях роста интенсивности информационных потоков и устаревания информации. Обратим внимание, что такое понимание информационной безопасности носит нетрадиционный характер и связано это с тем, что рассматриваемое понятие еще ожидает своей концептуализации в предметном поле социологической теории. Мы оставляем вопрос: может ли такое понимание информационной безопасности (в широком и узком смысле) являться развитием определения «защита информации и защита от информации»? Укладывается ли подобный подход в рамки определения информационной безопасности как «снятие информационной неопределенности относительно существующих угроз за счет контроля над мировым пространством и наличия возможностей, условий и средств для отражения этих угроз»? Или напрашивается более широкая концептуализация проблемы информационной безопасности, которая будет включать традиционное определение «защита информации и от информации» как частный случай?

\section{Библиография:}

1. Арсентьев М.В.К вопросу о понятии «Информационной безопасности» // Информационное общество, 1997. № $4-6$.

2. Говорунов А. В. Человек в ситуации виртуальной реальности // Информационное общество. 2001, № 1 .

3. Доктрина информационной безопасности Российской Федерации. Утверждена Президентом РФ 9 сентября 2000 г., № Пр-1895 // Российская газета. 2000. 28 сент.
4. Илюшенко В. Н. Информационная безопасность общества / Учебное пособие для ВУЗов. - Томск: Томский государственный университет систем управления и радиоэлектроники, 1998.

5. Кнорр Цетина К. Объектная социальность: общественные отношения в постсоциальных обществах знания // Журнал социологии и социальной антропологии. 2002. Т. V. № 1.

6. Расторгуев С. П. Основы информационной безопасности / Учеб. пособие для студ. высших учебных заведений. - М.: Издательский центр «Академия», 2009.

7. Российская Федерация. Законы. Об информации, информационных технологиях и о защите информации: Федеральный Закон РФ // Российская газета. 2006. 29 июля.

8. Тоффлер Э. Шок будущего / Пер. с англ. - М.: ООО «Издательство АСТ», 2001.

9. Игнатьев В. И., Владимирова Т. В., Степанова А. И. Социальная система как информационное взаимодействие: коллективная монография / В. И. Игнатьев, Т. В. Владимирова, А. Н. Степанова. - Новосибирск: Изд-во НГТУ, 2009.

10. Giddens A. Moderniti and self-idenliti. - Stanford (Cal.) Stanford univ. press, 1991.

\section{References (transliteration):}

1. Arsent'ev M. V. K voprosu o ponyatii «Informacionnoy bezopasnosti» // Informacionnoe obschestvo, 1997. № $4-6$.

2. Govorunov A. V. Chelovek v situacii virtual'noy real'nosti // Informacionnoe obschestvo. 2001, № 1.

3. Ilyushenko V. N. Informacionnaya bezopasnost' obschestva / Uchebnoe posobie dlya VUZov. Tomsk: Tomskiy gosudarstvennyy universitet sistem upravleniya i radioelektroniki, 1998.

4. Knorr Cetina K. Ob'ektnaya social'nost': obschestvennye otnosheniya $\mathrm{v}$ postsocial'nyh obschestvah znaniya // Zhurnal sociologii i social'noy antropologii. 2002. T. V. № 1.

5. Rastorguev S. P. Osnovy informacionnoy bezopasnosti / Ucheb. posobie dlya stud. vysshih uchebnyh zavedeniy. - M.: Izdatel'skiy centr «Akademiya», 2009.

6. Toffler E. Shok buduschego / Per. s angl. - M.: OOO «Izdatel'stvo AST», 2001.

7. Ignat'ev V. I., Vladimirova T. V., Stepanova A. I. Social'naya sistema kak informacionnoe vzaimodeystvie: kollektivnaya monografiya / V. I. Ignat'ev, 
DOI: $10.7256 / 2073-8560.2013 .4 .7476$

При цитировании этой статьи сноска на dоі обязательна

Национальная безопасность 4(27) • 2013

T. V. Vladimirova, A. N. Stepanova. - Novosibirsk: Izd-vo NGTU, 2009.

8. Giddens A. Moderniti and self-idenliti. - Stanford (Cal.) Stanford univ. press, 1991. 